\title{
Technology: A Friend or Foe? Do Electronic Health Records Increase Burn Out Amongst Anaesthesiologists?
}

\author{
Poonam S Ghodki ${ }^{1}$
}

3D total laparoscopic hysterectomy in progress under general anaesthesia; steep head low, everyone delighted to see the $3 \mathrm{D}$ picture on screen with the goggles including the anaesthesia resident. I enter the OT (needless to say that as a senior one has to supervise more than one OT at a time). The high-end Anaesthesia machine standing tall inside the OT with all the sophisticated monitoring gadgets. I look at the ventilatory pattern on monitor: et $\mathrm{CO}_{2}$ graph upsloping with a value of $42 \mathrm{~mm}$ of $\mathrm{Hg}$, airway pressure $26 \mathrm{~mm}$ of $\mathrm{Hg}$ and rising! I ask a rhetoric question to my resident as to where his attention is and to my dismay, he expresses his dissatisfaction that the monitors neither give us alarms against rising et $\mathrm{CO}_{2}$ or airway pressure nor do they warn us about changing capnograph slopes!! I am appalled.

THROWBACK-Not long time ago when we were residents, we used our 'educated hands' to monitor the airway pressure with manual ventilation. Differential diagnosis of tight bag used to be one of the favourite questions seniors used to ask us during on-table teaching. We had no et $\mathrm{CO}_{2}$ monitor then (the mandatory minimum monitoring standard); leave alone the hi-tech ventilatory gadgets and associated airway gas monitoring. Sooner the educated hand was replaced by ventilator and arguments will continue whether to declare this as a loss of clinical skill; an unresolved riddle due to paucity of evidence. The least that I can say is with the hand on pulse and bag in hand, we used to 'stay connected' to the patient; with the technical advances this connection got lost.

Does this make the ventilator and the advances in monitoring evil?? Obviously not. The advances in science and technology are not only for our comfort but they also play a pivotal role in improving patient's safety and offering better patient care. Over years surgery has advanced enormously and most of these developments are attributed to advances in the field of anaesthesia which has evolved itself from the Stone Age to modern era (Figure 1). And no prize for telling what has made sitting at leisure possible for anaesthetist. Yes, technical advances it is! Scientific innovation has undoubtedly made our lives easy but that should not place our patient's life at stake. None of the anaesthetists today would like to reverse back time and work in the circumstances prevalent some 15 years ago. Nevertheless they may be having many fond memories of those times, but the reluctance to work in the past is all attributed to unavailability of the technical advances then. If I take myself 15 years back, I would find myself in urosurgery
OT doing a case of laparoscopic nephrectomy (proposed as laparoscopic sos open and we used to ridicule it as laparoscopic followed by open!) WITHOUT etCO $\mathrm{O}_{2}$ monitoring. A GA without capnography, a laparoscopic case without capnography, a major case without capnography...this thought itself throws shiver down my spine today. We used to put an arterial line merely to monitor $\mathrm{paCO}_{2}$. And what is the situation today? Experienced surgeons now usually finish the laparoscopic nephrectomy in less than 3 hours and we as anaesthetists now have Drager primus workstation and I needn't discuss any further about the luxury it offers. We get minute details of respiratory mechanics and cardiac hemodynamics; meanwhile we also have facilities to ensure adequate depth of anaesthesia.

What else can one ask for?! Nonetheless, we have been gifted more by science and our engineering colleagues. Anaesthesia today in 'general' has moved from 'general' anaesthesia to balanced anaesthesia technique involving more and more regional blocks. If there is a nerve, it can be blocked! And what has made this possible? Perhaps; the ultrasound. Talking about technical advances and ignoring ultrasound is unimaginable. Ultrasound has made real time visualisation possible, has provided precision for nerve blocks thereby increasing success rate and decreasing the rate of complications [1]. As a resident, we used to give nerve blocks through landmark technique or under peripheral nerve stimulator guidance. Do not render us in abjection for this as we used to thoroughly enjoy applying anatomical knowledge in achieving successful blocks. It is true that when you place the ultrasound probe, you get to see what you intend to block, but your eyes cannot see what your brain does not know. Therefore, even with the advent of ultrasound one has to be thorough with the anatomy and its sine qua non that no machine can replace one's clinical acumen.

I will have to skip many other technical advances as discussing all of them would be beyond the scope of this write-up. Yet, without fail I would like to mention the advanced airway gadgets starting from supraglottic devices to fiberoptic scope and videolaryngoscopes. Residents are now getting trained with videolaryngoscopes in their first week of residency itself. On one social media group there was an argument as to whether acquiring direct laryngoscopy skill mandated for today's generation? I relinquished the idea as I strongly believe that all the future lot of anaesthetists; no matter how advancedly trained;

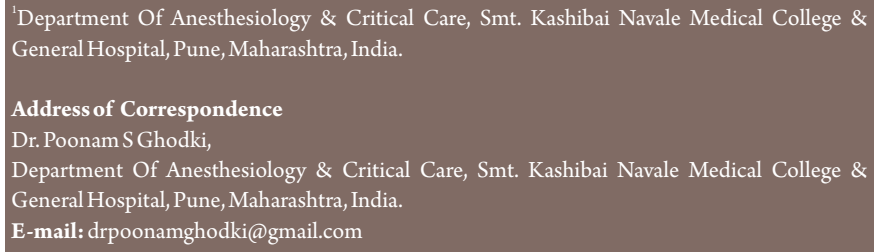

(n) 


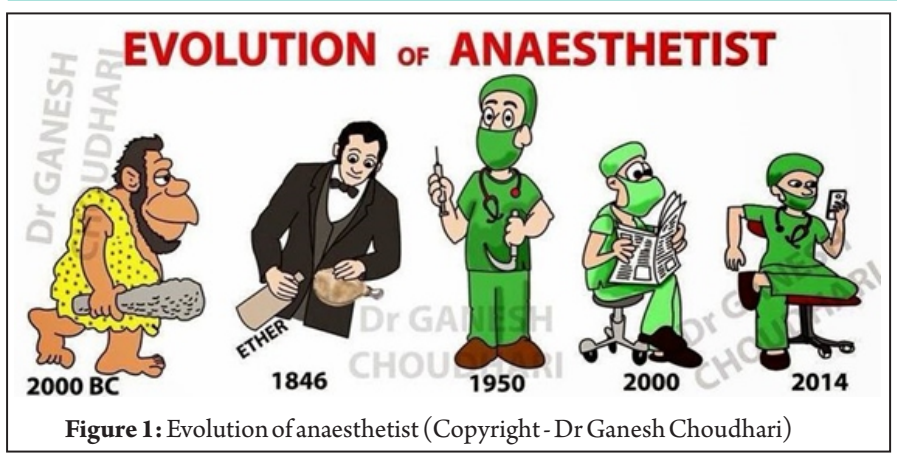

SHOULD learn the basics in anaesthesia practice first.

Technology advanced, not only in providing us with devices that have become an integral part of our armamentarium, but the advances also extended to aid us in easing our paperwork too. Indeed, we are talking about electronic health records (EHR) [2]. Started as a formula for centralised recordkeeping and improving communication and access, maintaining EHR got popularised as a saviour of paper enabling green revolution. In the bargain, unknowingly EHR increased the burden on clinicians and became a precipice for stress leading to burn out syndrome. How does the conglomeration of technical advances and EHR lead to burn out? Let me try to explain this with examples. We all know how USG has tremendously improved patient's safety and widened the horizons of various procedures done by the anaesthetists. And come to documentation! Maintaining records in lines with the PCPNDT act definitely is stressful and is a horrendous obstacle for progress in anaesthesia practice. Another example is the documentation of narcotics and induction agent usage. Anaesthetists perpetually avoid using drugs, which albeit maybe strongly indicated, but better not used to escape the tiring EHR procedure. Nobody wants to face unwarranted legal allegations. But does that solve the problem? Instead of running away from the stressful situation we can have some proactive measures to halt the progress of burn out syndrome originating from EHR. Although researchers have found that EHR related stress and burn out is dependent on the physician's specialty with less than $10 \%$ incidence amongst anaesthetists, it is likely to rise with improving measure of diagnoses and reporting [3].

Anaesthesia is a specialty where stress is inherent and I believe subtle amount of stress rather helps in improving the performance. But the stress from maintaining EHR is difficult to manage; it can cause collateral damage and lead to burn out in the anaesthetist. While stress by aetiology occurs when an individual's ability to cope and deal with demands is exceeded, burn out is a severe form and is syndromic with many components. Burn out is characterised by depersonalisation, emotional exhaustion and loss of sense of achievement [4]. Burn out from EHR happens because of too little time for documentation; time spent at home managing records and EHR user interfaces that are not intuitive to the physicians who use them. And because here we are talking of burn out pertinent to EHR, preventing it becomes more feasible. Multimodal technique beginning early in medical education, deploying factors that keep physicians more buoyant, teaching them skills to improve the emotional quotient and enhancing the EHR user interface can together contribute in dealing with burnout amongst us. A classic 3R's approach has been described in literature to tackle with burnout syndrome in general. The 3R's stand for Recognition, Reversal and Resilience and are self explanatory [5]. We as anaesthetist have an indomitable spirit, call it a boon or a curse, but we definitely have expertise in multitasking and if properly trained we can get rid of burn out arising from $\mathrm{EHR}$.

To conclude, our friendly neighbourhood's uncle (yes, you guessed it right, its uncle Ben from Spiderman) once said "With great powers come great responsibilities"; and this phrase is very apt for our situation. Despite the many misgivings, technical advances and the modern devices have become an essential component of anaesthesia practice today. So yes, technology is not our foe but friend; provided we put it to optimum use for offering better patient services and care and at the same time taking adequate care of our own physical and mental health.

DIY: As technology advances, it reverses the characteristics of every situation again and again. The age of automation is going to be the age of 'do it yourself'-Marshall McLuhan.

Declaration of patient consent: The authors certify that they have obtained all appropriate patient consent forms. In the form, the patient has given his consent for his images and other clinical information to be reported in the Journal. The patient understands that his name and initials will not be published, and due efforts will be made to conceal his identity, but anonymity cannot be guaranteed.

\section{Conflict of interest: Nil Source of support: None}

\section{References}

1. Grau T. Ultrasonography in the current practice of regional anaesthesia. Best Practice and Research Clinical Anaesthesiology 2005; 19: 175200.

2. Simpao AF, Galvez JA, Cannesson M. Should we fear computers or the lack of them? Technology, digital quality improvement, and the care redesign process. Anesthesiology 2017; 126:369-70.

3. Jang J, Yu SH, Kim CB, Moon Y, Kim S. The effects of an electronic medical record on the completeness of documentation in the anesthesia record. Int J Med Inform 2013; 82: 702-7.

4. Rama-Maceiras P., Jokinen J., Kranke P. Stress and burnout in anaesthesia: A real world problem? Current Opinion in Anaesthesiology.2015;28(2):151-158

5. Panagioti M., Panagopoulou E., Bower P., et al. Controlled interventions to reduce burnout in physicians a systematic review and meta-analysis. JAMA Internal Medicine. 2017;177(2):195-205.

\section{How to Cite this Article}

Ghodki PS. | Technology: A Friend or Foe? Do Electronic Health Records Increase Burn Out Amongst Anaesthesiologists? | Journal of Anaesthesia and Critical Care Case Reports | September-December 2021; 7(3): 02-03. 